\section{Highly anxious dental patients report more pain during dental injections}

\author{
A. J. van Wijk' and P. C. Makkes²
}

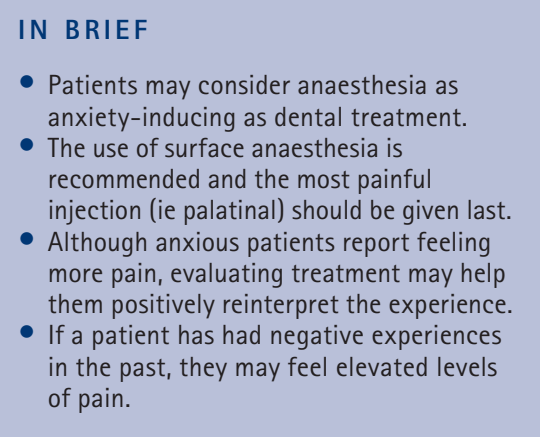

\begin{abstract}
Objectives In the present study, the relationship between anxiety and pain was investigated using a clinically relevant sample and stimulus. Methods A sample of highly anxious dental patients $(n=23)$ and a sample of 'normal' subjects ( $n$ $=57$ ) were compared with respect to the duration and intensity of pain while receiving a dental anaesthetic injection. Results As expected, highly anxious dental patients indicate more pain, which is of longer duration, than normal patients. Most predictive for the amount of pain felt was the pain felt during a previous injection. Conclusion Dentists should be aware that anxious dental patients with a negative experience regarding dental injections may feel elevated levels of pain which most likely leads to negative expectations for the future.
\end{abstract}

\section{INTRODUCTION}

There is substantial evidence that anxiety can increase perceptions of pain. Weisenberg et al. ${ }^{1}$ have already proposed that anxiety which is relevant to the pain-inducing stimulus will exacerbate pain, whereas anxiety that is irrelevant to the pain-inducing stimulus would reduce the experience of pain. In line with this proposition, $\mathrm{Al}$ Absi and Rokke ${ }^{2}$ argue that much of the literature supporting a positive correlation between anxiety and pain refers to a research context where anxiety is related to the painful stimulus. Arntz and collegues claim that this is due to attentional mechanisms..$^{3-6}$ This claim is supported by more recent studies stating that anxiety or fear can have a pain-increasing effect due to attentional bias towards the painful stimulus ${ }^{7}$ or pain-related sensations. ${ }^{8}$ According to Litt, ${ }^{9}$ nowhere is the

"Department of Social Dentistry and Behavioural Sciences, Academic Centre for Dentistry Amsterdam (ACTA), Universiteit van Amsterdam and Vrije Universiteit, Louwesweg 1, 1066 EA Amsterdam, The Netherlands; ${ }^{2}$ Centre for Special Dental Care (Stichting voor Bijzondere Tandheelkunde), Louwesweg 1, 1066 EA Amsterdam, The Netherlands

${ }^{*}$ Corresponding author: Dr Arjen J. van Wijk Email:a.vwijk@acta.n

Online article number E7

Refereed Paper - accepted 28 January 2008

DOI: 10.1038/sj.bdj.2008.583

${ }^{\circ}$ British Dental Journal 2008; 205: E7 relationship between anxiety and pain better seen than in dentistry.

Early studies concerning the relationship between anxiety and pain in dentistry were performed using electrical shocks. Lautch ${ }^{10}$ found that high anxious subjects had lower pain thresholds than low anxious subjects. Klepac et al. ${ }^{11}$ compared dental phobic and non-phobic subjects on the level of pain felt during arm shock and tooth shock. Dental phobic subjects reported the tooth shock to be more painful than non-phobic subjects, but reported equal pain during the arm shock. Bernstein et al. ${ }^{12}$ reported that anxious patients report more pain during previous dental procedures. Vassend $^{13}$ measured dental anxiety and pain during dental procedures (retrospectively and prospectively) and found positive correlations. Eli et al. ${ }^{14}$ investigated acute pain perception under an oral surgery procedure of implant insertion. They found that the best predictor of pain experienced is the level of state anxiety. Other studies investigating pain during scaling procedures ${ }^{15,16}$ and pain after periodontal surgery ${ }^{17}$ also reported a positive correlation between dental anxiety and pain. Most recently, dental anxiety and pain sensitivity were combined to successfully predict expected and experienced pain during stressful dental procedures. ${ }^{18}$ Finally, the earlier mentioned attentional bias is also present in highly anxious dental patients. ${ }^{19}$

Although there is considerable evidence for the relationship between anxiety and pain in dentistry, some limitations concern the ecological validity of stimulus and sample. While some studies make use of highly anxious dental patients, the stimulus is usually experimental (for instance tooth shock). On the other hand, studies using actual painful of stressful dental procedures (drilling, extractions, root canal therapy) commonly make use of artificially created 'highly anxious patients'. That is, a group of patients or freshmen is divided in a low-fear group and a highfear group based on the median dental anxiety score of the whole group. It goes without saying that these "highly anxious' patients may differ strongly from patients who are treated at a dental fear clinic (let alone patients so fearful they will not even go there). Therefore, the present study set out to investigate the relationship between dental anxiety and pain using a clinically relevant sample and stimulus. Highly anxious dental patients (treated at a dental fear clinic) and normal patients are compared with respect to pain experience while receiving a dental injection. Our main hypothesis is that highly anxious dental patients experience more pain during dental 
injections than normal dental patients. In addition, associations between previous, present and future experience with dental injections are explored.

\section{MATERIAL AND METHODS}

\section{Subjects}

Two samples of patients were used in the present study; a sample ( $\mathrm{n}=23$, mean age $=39.5$ yrs, standard deviation (SD) $=13.4$ ) of highly anxious dental patients (9 male, 14 female) treated at a dental fear clinic (SBT*) in Amsterdam, and a sample $(\mathrm{n}=57$, mean age $=38.2 \mathrm{yrs}, \mathrm{SD}$ $=15.2$ ) of 'normal' patients (36 male, 21 female) collected at three general dental practices located in Zaandam, Amsterdam and at ACTA. Inclusion criteria were a minimum age of 18 years and sufficient understanding of the Dutch language. Data collection took place from October to December 2004.

At this specific dental fear clinic,* patients can only apply for treatment when they fulfill two strict criteria. First, a number of anxiety questionnaires are filled out and patients require certain minimal scores. The questionnaires and their minimum scores are: a dental anxiety scale (ie a VAS) cut-off $=8$; the DAS (dental anxiety scale) ${ }^{20}$ cut-off $=15$; the S-DAI (short version of the Dental Anxiety Inventory ${ }^{21}$ cut-off $=28$; and the DPFR (duration of psycho-physiological reactions $)^{22}$ cut-off $=7$. Secondly, during a screening interview it should become clear that the patient has shown severe avoidance behaviour in the past, and has been/still is difficult to treat. Although the sample of patients obtained from the three practices may also consist of patients experiencing moderate to severe anxiety, on average, their anxiety levels should be incomparable to those of the highly anxious patients treated at the dental fear clinic.

\section{Material}

\section{Pain}

The intensity and duration of pain following a dental injection (see below) were measured. Subjects were requested

${ }^{*}$ Centre for Special Care; Stichting Bijzondere Tandheelkunde (SBT); located at ACTA, Amsterdam to indicate the duration of their pain by raising their hand as long as they felt pain as a result of and next to the injection. Time was measured using a stopwatch by one independent research assistant. After the injection, prior to starting treatment, subjects were asked to rate the painfulness of the injection on a numerical rating scale (NRS) from 0 (no pain) to 10 (worst pain possible). ${ }^{23}$

\section{Dental anxiety}

The S-DAI is the short version of the Dental Anxiety Inventory, ${ }^{24}$ which has shown to be reliable and valid. ${ }^{21}$ It contains nine items that are answered on a five-point Likert-type scale. An example is 'I become nervous when the dentist invites me to sit down into the chair'.

\section{State anxiety}

Besides a general measure of dental anxiety (the S-DAI), anxiety was also measured using the following questions: 'How anxious are you at the moment?' and 'How anxious are you about receiving an injection?' Answers were given on a NRS from 0 (not anxious at all) to 10 (extremely anxious).

\section{Experience with dental injections}

Fear of dental injections may consist of several factors such as general fear of injections (including pain), fear related to local anaesthesia (such as side effects), fear of acquired disease and fear of injury. ${ }^{25}$ For the present study, three items were used to assess previous experience with dental injections in terms of confidence in the injection, pain felt during injections and anxiety related to injections. All answer scales were transformed in such a way that a higher score indicates more confidence, pain and anxiety. One item was used to assess anxiety regarding future injections (this was answered after treatment). Answers were given on a five-point answer scale. These four items were derived from a study by Matthews et al. ${ }^{26}$

\section{Anaesthetic location}

Clinical experience points out that some injections are more painful than others. In the present study, mandibular, buccal and palatinal injections were distinguished. The palatinal injections were considered to be the most painful.

\section{Procedure}

The research design was discussed with and approved by the head of the dental fear clinic (SBT). In addition, prior to approaching a highly anxious dental patient, the respective treating dentist was contacted to make sure that the experiment would not interfere with treatment and would not be too much of a burden to the patient. On three occasions, the treating dentist indicated that he/she felt that the respective patient was not suitable for inclusion in the study. After obtaining consent from the treating dentist, the patient was approached in the waiting room and asked to participate. Patients were told that the aim of the research was to study how (anxious) patients deal with dental anaesthesia, without mentioning pain. Upon consent, questionnaires were filled out in the waiting room. Next, treatment took place. Prior to the injection, instructions were given about raising the hand while feeling pain. About half a minute after the injection (after lowering the hand) patients were asked to rate the painfulness of the injection on a NRS. The investigator left the room at that point and waited for the patient. After treatment, one question regarding future dental injections had to be answered. All patients signed informed consent and were given the opportunity to receive information regarding the aim and general outcome of the study.

\section{Statistical analysis}

The Chi-square test was used to examine the distribution of categorical variables. MAN(C)OVA was used to test for mean differences on the set of independent variables, corrected for different covariates. Independent samples t-tests were used to compare mean scores between samples. ANOVA was used to compare multiple mean scores. Pearson's correlation coefficient was used as a measure of linear association for quantitative variables and Kendall's taub was used for ordinal variables. Alpha was set at 0.05 . 


\section{RESULTS}

\section{Assumption regarding samples}

First, it was tested whether the highly anxious dental patients indeed clearly differed from the 'normal' patients with respect to dental anxiety. The t-tests revealed that highly anxious dental patients report that they feel more anxiety prior to treatment $(\mathrm{t}(78)=-11.24$, $\mathrm{p}<0.001)$, more anxiety for the local anaesthesia $(\mathrm{t}(78)=-6.94, \mathrm{p}<0.001$ ) and more dental anxiety (S-DAI; $t$ (76) $=-15.89, p<0.001)$ than normal patients (Table 2). This result clearly supports the assumption of having a 'normal' sample and a 'highly anxious' sample of dental patients.

\section{Anaesthetic location}

A total of 80 dental injections were included in the study. The Chi-square test shows that the distribution of the different anaesthetic locations was approximately equal in the two samples $\left(\chi^{2}(2)=5.25, p=0.073\right)$. However, Table 1 shows that the mandibular and palatinal injection was used less frequently in the sample with highly anxious dental patients. In addition, whenever the null hypothesis is equal to the research hypothesis (we would like to show that $\mathrm{H}_{0}$ holds true) it is advisable to set alpha to $0.20 .{ }^{27,28}$ Using this level of significance, it is concluded that the different anaesthetic locations were not equally distributed across samples. As such, the different anaesthetic locations were compared with respect to pain.

ANOVA shows that the palatinal injection was most painful with respect to intensity of pain $(\mathrm{F}(2,77)=4.96, \mathrm{p}$ $<0.01$ ), while the mandibular and buccal location were considered to be equally painful. The locations did not differ regarding the duration of the pain. Given the distribution of anaesthetic locations over the samples it is possible that the mean pain score of highly anxious dental patients will be lower because they received a relatively small number of palatinal injections.

\section{Highly anxious and normal dental patients}

Our main hypothesis was that highly anxious dental patients feel more pain

Table 1 Distribution of anaesthetic location over samples

\begin{tabular}{l|l|l|l|l} 
& Palatinal & Buccal & Mandibular & Total \\
\hline Highly anxious & 2 & 13 & 8 & 23 \\
\hline Normal & 15 & 18 & 24 & 57 \\
\hline Total & 17 & 31 & 32 & 80
\end{tabular}

Table 2 Mean scores (standard deviation) on the dependent variables and results of the independent samples $t$ test

\begin{tabular}{l|l|l}
\hline & \multicolumn{2}{|c}{ Samples } \\
\hline Variables & Highly anxious patients & Normal patients \\
\hline Pain in seconds & $8.83(14.89)^{a}$ & $1.99(4.76)$ \\
\hline Pain intensity & $3.04(3.18)^{a}$ & $1.81(2.07)$ \\
\hline Anxiety now & $6.96(1.90)^{b}$ & $1.35(2.07)$ \\
\hline Anxiety for anaesthetic & $6.30(3.01)^{b}$ & $1.98(2.30)$ \\
\hline Confidence in anaesthetic & $2.13(1.18)^{a}$ & $1.67(0.74)$ \\
\hline Pain with last anaesthetic & $1.61(1.34)^{b}$ & $0.88(0.73)$ \\
\hline Anxiety during last anaesthetic & $4.17(0.94)^{b}$ & $2.72(1.09)$ \\
\hline Anxiety future anaesthetic & $3.26(1.01)^{b}$ & $2.21(0.99)$ \\
\hline Dental anxiety (S-DAl) & $40.33(6.58)^{b}$ & $15.44(5.98)$ \\
\hline$a=p<0.05, b=p<0.01$ & & \\
\hline
\end{tabular}

Table 3 Kendall's tau b between pain, experience with and expectancies about dental injections

\begin{tabular}{|c|c|c|c|c|c|}
\hline & I Confidence & $\begin{array}{l}\text { II } \\
\text { Pain }\end{array}$ & $\begin{array}{l}\text { III } \\
\text { Anxiety }\end{array}$ & $\begin{array}{l}\text { IV } \\
\text { Future }\end{array}$ & $\begin{array}{l}\text { Pain } \\
\text { intensity }\end{array}$ \\
\hline I & -- & & & & \\
\hline II & $-0.25^{a}$ & -- & & & \\
\hline III & $-0.31^{b}$ & $0.49^{b}$ & -- & & \\
\hline IV & $-0.23^{a}$ & $0.42^{b}$ & $0.64^{b}$ & -- & \\
\hline Pain_i & -0.16 & $0.47^{b}$ & $0.41^{\mathrm{a}}$ & $0.45^{b}$ & -- \\
\hline Pain_d & -0.19 & $0.36^{6}$ & $0.28^{\mathrm{a}}$ & $0.42^{b}$ & $0.70^{b}$ \\
\hline
\end{tabular}

than do normal patients. First, the two samples were compared on the dependent variables (pain intensity and duration) using a MANOVA. Results showed a significant main effect for type of sample $(F(2,77)=5.23, p<0.007)$. Subsequent univariate analysis showed that for both the duration of pain $(\mathrm{F}(1,78)=$ 9.73, $\mathrm{p}<0.003)$ and for intensity of pain $(\mathrm{F}(1,78)=4.21, \mathrm{p}<0.043)$, highly anxious dental patients score significantly higher than normal patients. After correcting for dental anxiety (ie the SDAI) as a covariate, no more significant differences could be shown ( $F(2,74)$ $=3.05, \mathrm{p}$ <0.053). A similar result was obtained after entering previous experience with dental injections (item 2, ie pain felt during last injection; $\mathrm{F}(2,76)=$ $2.77, \mathrm{p}<0.069)$. The other variables were not significant as covariates. The mean scores on the dependent variables and their comparisons are presented in Table 2 (not corrected for covariates). 


\section{Experience and expectancies regarding dental injections}

To examine how previous experience with dental injections, experience at present and expectancies for future dental injections are associated, Kendall's tau-b was calculated between all relevant variables. The result is presented in Table 3.

From Table 3 it can be seen that a longer duration of pain was associated with more pain intensity. Again, this result points out that more anxiety is associated with more pain. Specific anxiety related to receiving an injection showed the highest correlation with pain, although differences were small.

The amount of pain felt during the last injection was most strongly related to the level of anxiety for the present anaesthetic. Finally, the amount of pain felt during the present anaesthetic was associated most with anxiety for future anaesthetic injections.

\section{DISCUSSION}

The main purpose of the present study was to examine the relationship between anxiety and pain within a clinically relevant sample using a clinically relevant painful stimulus. A sample of highly anxious dental patients and a sample of normal patients were compared with respect to the intensity and duration of pain felt while receiving an anaesthetic dental injection. Results clearly show that highly anxious dental patients feel substantially more pain, and of longer duration, than do normal patients. Given the fact that the palatinal injection proved most painful and the fact that highly anxious patients hardly received palatinal injections, the difference in pain experience between highly anxious and normal dental patients is most likely even larger than found in the present study. The result coincides with the studies mentioned in the introduction but has more ecological validity due to sample and stimulus choice. In addition, all data were collected within a dental context (questionnaires in waiting room, pain in treatment room) which might have an effect on pain experience as well. ${ }^{29}$ It may be clear that the number of highly anxious dental patients used in this study was limited. However, this population is hard to access, especially when this means intervening with treatment as usual. In fact, a number of times (three) the treating dentist objected to participating for this reason.

Whereas Milgrom et al. ${ }^{25}$ gave excellent clinical recommendations on how to handle patients with specific types of fear of dental injections, the present study suggests that a number of these patients report that they do feel more pain, which could be an explanation for their fears but also vice versa (their fear leads to a increased pain perception). Indeed, a number of recent studies are aimed at improving the prediction of pain experienced during dental procedures, eg a study by Klages et al. ${ }^{18}$ where trait anxiety combined with pain sensitivity ${ }^{30}$ was most predictive for the amount of experienced pain. Also anxiety sensitivity is increasingly related to pain-related fears and anxiety. ${ }^{31-33}$ Fear of pain itself is a highly relevant concept in pain research. ${ }^{34}$ In fact, it led one of the present authors to develop the Fear of Dental Pain questionnaire (FDP). ${ }^{35} \mathrm{~A}$ recent study points out that the concept may directly be related to elevated pain levels during periodontal probing. ${ }^{36}$ The latter questionnaire was not used in the present study because the suggestive nature of the items was judged to have possible negative effects on the sample of highly anxious dental patients. That is, we were interested to see whether patients feel more pain because they are anxious, not to make them more anxious and see if this affects the pain experience.

When trying to predict the intensity of pain, the anxiety for the local anaesthetic and injection location were significant predictors. For the duration of pain, only anxiety at that particular moment was predictive. When dividing the samples, no significant prediction could be determined for the sample of highly anxious patients. The latter can be explained by a combination of a bottom effect (low pain during injections), ceiling effect (all highly anxious) and lack of statistical power. Inspection of scatter plots indeed confirms the expectation that a relation between the duration and intensity of pain could be shown in a scenario with more highly anxious dental patients.
The results concerning earlier experiences with dental injections are also quite clear. More pain during previous dental injections is associated with more anxiety for the present dental injection. More pain during the present dental injection is associated with more anxiety for future injections. This result is consistent with another study reporting an association between the amount of pain felt during an injection and the estimated level of anxiety for an injection within a number of days. ${ }^{37}$

One patient's response was particularly remarkable. During the injection, she held her hand up for about 30 seconds. Upon asking to rate the pain that she felt, she indicated that it did not hurt at all (in hindsight). It appears that this person felt what she was expecting to feel. However, when looking back she had to conclude that it did not hurt at all. This subject's data was not included in the analysis. However, it does indicate that it may be very useful to evaluate treatment with some patients to help them positively reinterpret the experience.

To conclude, a strong relationship was found between anxiety and pain. Highly anxious dental patients feel more pain, which lasts longer. The clinical relevance of the study is obvious. Especially with highly anxious patients, palatinal injections should be given last. The use of surface anaesthesia is recommendable to reduce the sharpest pain somewhat. In addition, if a patient has had negative experiences in the past with dental injections and the patient is anxious, the treating dentist should be aware that the patient may feel elevated levels of pain, causing anxious feelings for future injections, perhaps even leading to avoidance of dental care. Taking more time for patients (for instance following the recommendations of Milgrom et $a l.)^{25}$ and making an effort to reduce levels of anxiety can reduce patient's pain experience, thereby making the dental visit more pleasant for both patient and dentist.

1. Weisenberg M, Aviram O, Wolf Y, Raphaeli N. Relevant and irrelevant anxiety in the reaction to pain. Pain 1984; 20: 371-383.

2. Al Absi M, Rokke P D. Can anxiety help us tolerate pain? Pain 1991; 46: 43-51.

3. Arntz A, Dreessen L, Merckelbach H. Attention, not 
anxiety, influences pain. Behav Res Ther 1991; 29: 41-50.

4. Arntz A, de Jong P. Anxiety, attention and pain. J Psychosom Res 1993; 37: 423-431.

5. Arntz A, Dreessen L, De Jong P. The influence of anxiety on pain: attentional and attributional mediators. Pain 1994; 56: 307-314.

6. Janssen S A, Arntz A. Anxiety and pain: attentional and endorphinergic influences. Pain 1996; 66: $145-150$.

7. Rhudy J L, Meagher M W. Fear and anxiety: divergent effects on human pain thresholds. Pain 2000; 84: 65-75.

8. Keogh E, Ellery D, Hunt C, Hannent I. Selective attentional bias for pain related stimuli amongst pain fearful individuals. Pain 2001; 91: 91-100.

9. Litt M D. A model of pain and anxiety associated with acute stressors: distress in dental procedures. Behav Res Ther 1996; 34: 459-476.

10. Lautch H. Dental phobia. Br J Psychiatry 1971; 119: 151-158.

11. Klepac R K, Dowling J, Hauge G. Characteristics of clients seeking therapy for the reduction of dental avoidance: reactions to pain. J Behav Ther Exp Psychiatry 1982; 13: 293-300.

12. Bernstein D A, Kleinknecht R A, Alexander LD. Antecedents of dental fear. J Public Health Dent 1979; 39: 113-124.

13. Vassend O. Anxiety, pain and discomfort associated with dental treatment. Behav Res Ther 1993; 31: 659-666.

14. Eli I, Bar-Tal Y, Fuss Z, Silberg A. Effect of intended treatment on anxiety and on reaction to electric pulp stimulation in dental patients. J Endod 1997; 23: 694-697.

15. Sullivan M J L, Neish N R. Catastrophizing, anxiety and pain during dental hygiene treatment.
Community Dent Oral Epidemiol 1998; 26: 344-349.

16. Chung D T, Bogle G, Bernardini M, Stephens D,

Riggs M L, Egelberg J H. Pain experienced by patients during periodontal maintenance. J Periodontol 2003; 74: 1293-1301.

17. Croog S H, Baume R M, Nalbandian J. Pre-surgery psychological characteristics, pain response, and activities impairment in female patients with repeated periodontal surgery. J Psychosom Res 1995; 39: 39-51.

18. Klages U, Ulusoy O, Kianifard S, Wehrbein H. Dental trait anxiety and pain sensitivity as predictors of expected and experienced pain in stressful dental procedures. Eur J Oral Sci 2004; 112: 477-483.

19. Johnson B H, Thayer J F, Laberg J C et al. Attentional and physiological characteristics of patients with dental anxiety. J Anxiety Disord 2003; 17: 75-87.

20. Corah N L. Development of a dental anxiety scale. J Dent Res 1969; 48: 596.

21. Aartman I H A. Reliability and validity of the short version of the Dental Anxiety Inventory. Community Dent Oral Epidemiol 1998; 26: 350-354.

22. van der Zijpp A T, ter Horst $G$, de Jongh A, Makkes $P$ C. Treatment for dental anxiety. Evaluation of treatment of patients with anxiety. Ned Tijdschr Tandheelkd 1996; 103: 213-215 [in Dutch].

23. Turk D C, Melzack R. Handbook of pain assessment. New York: The Guilford Press, 1992.

24. Stouthard M. Angst voor de tandheelkundige behandeling. Ontwikkeling en validatie van een vragenlijst voor onderzoek en praktijk. Amsterdam: University of Amsterdam, 1989. PhD Thesis.

25. Milgrom $P$, Coldwell S E, Getz T, Weinstein $P$, Ramsay D S. Four dimensions of fear of dental injections. J Am Dent Assoc 1997; 128: 756-766.

26. Matthews D C, Rocchi A, Gafni A. Factors affecting patients' and potential patients' choices among anaesthetics for periodontal recall visits. J Dent 2001: 29: 173-179.

27. Elstrodt M, Mellenbergh $\mathrm{G} J$. Eén minus de vergeten fout. Ned Tijdschr Psychol 1978; 33: 33-49.

28. Hoogstraten J, Koele P. Cohen's foute berekeningen van de vergeten fout. Tijdschr Onderwijsresearch 1981; 6: 174-181.

29. Dworkin S F, Chen A C. Pain in clinical and laboratory contexts. J Dent Res 1982; 61: 772-774.

30. Gross P R. Is pain sensitivity associated with dental avoidance? Behav Res Ther 1992; 30: 7-13.

31. Zvolensky M J, Goodie J L, McNeil D W, Sperry J A Sorrell J T. Anxiety sensitivity in the prediction of pain-related fear and anxiety in a heterogeneous chronic pain population. Behav Res Ther 2001; 39: 683-696.

32. Keogh $E_{1}$ Cochrane M. Anxiety sensitivity, cognitive biases, and the experience of pain. J Pain 2002; 3: 320-329

33. Norton $P$ J, Reid T, McIntyre M, Norton $G R$. Anxiety sensitivity and fear of pain in acute pain: mediator or moderator effects? Pain Res Manag 2004: 9: 100-101.

34. McNeil D W, Rainwater A J 3rd. Development of the fear of pain questionnaire - III. J Behav Med 1998; 21: 389-410.

35. van Wijk A J, Hoogstraten J. The fear of dental pain questionnaire: construction and validity. Eur J Oral Sci 2003; 111: 12-18

36. van Wijk A J, Hoogstraten J. Experience with dental pain and fear of dental pain. J Dent Res 2005; 84: 947-950.

37. Speirs A F, Taylor K H, Joanes D N, Girdler N M. A randomised, double blind, placebo-controlled, comparative study of topical skin analgesics and the anxiety and discomfort associated with venous cannulation. Br Dent J 2001; 190: 444-449. 